\title{
Comparisons of benefits and risks of single embryo transfer versus double embryo transfer: a systematic review and meta-analysis
}

Shujuan $\mathrm{Ma}^{1 \dagger}$, Yangqin Peng ${ }^{1 \dagger}$, Liang Hu${ }^{1}$, Xiaojuan Wang ${ }^{1}$, Yiquan Xiong ${ }^{2}$, Yi Tang $^{1}$, Jing $\operatorname{Tan}^{2^{*}}$ (D) and Fei Gong ${ }^{1 *}$

\begin{abstract}
Background: Evidence referring to the trade-offs between the benefits and risks of single embryo transfer (SET) versus double embryo transfer (DET) following assisted reproduction technology are insufficient, especially for those women with a defined embryo quality or advanced age.

Methods: A systematic review and meta-analysis was conducted according to PRISMA guidelines. PubMed, EMBASE, Cochrane Library and ClinicalTrials.gov were searched based on established search strategy from inception through February 2021. Pre-specified primary outcomes were live birth rate (LBR) and multiple pregnancy rate (MPR). Odds ratio (OR) with 95\% confidence interval $(\mathrm{Cl})$ were pooled by a random-effects model using R version 4.1.0.

Results: Eighty-five studies (14 randomized controlled trials and 71 observational studies) were eligible. Compared with DET, SET decreased the probability of a live birth (OR=0.78, 95\% Cl: $0.71-0.85, P<0.001, n=62)$, and lowered the rate of multiple pregnancy $(0.05,0.04-0.06, P<0.001, n=45)$. In the sub-analyses of age stratification, both the differences of $\operatorname{LBR}(0.87,0.54-1.40, P=0.565, n=4)$ and MPR $(0.34,0.06-2.03, P=0.236, n=3)$ between SET and DET groups became insignificant in patients aged $\geq 40$ years. No significant difference in LBR for single GQE versus two embryos of mixed quality [GQE +PQE (non-good quality embryo)] $(0.99,0.77-1.27, P=0.915, n=8)$, nor any difference of MPR in single PQE versus two PQEs $(0.23,0.04-1.49, P=0.123, n=6)$. Moreover, women who conceived through SET were associated with lower risks of poor outcomes, including cesarean section $(0.64,0.43-0.94)$, antepartum haemorrhage $(0.35,0.15-0.82)$, preterm birth $(0.25,0.21-0.30)$, low birth weight $(0.20,0.16-0.25)$, Apgar $1<7$ rate $(0.12,0.02-0.93)$ or neonatal intensive care unit admission $(0.30,0.14-0.66)$ than those following DET.
\end{abstract}

Conclusions: In women aged <40years or if any GQE is available, SET should be incorporated into clinical practice. While in the absence of GQEs, DET may be preferable. However, for elderly women aged $\geq 40$ years, current evidence is not enough to recommend an appropriate number of embryo transfer. The findings need to be further confirmed.

Keywords: Single embryo transfer, Double embryo transfer, Live birth rate, Multiple pregnancy rate, Perinatal complication

\footnotetext{
*Correspondence: tanjing84@outlook.com; gongfei0218@hotmail.com †Shujuan Ma and Yangqin Peng are joint first authors.

${ }^{1}$ Clinical Research Center for Reproduction and Genetics in Hunan Province, Reproductive and Genetic Hospital of CITIC-Xiangya, No. 567, Tongzipo West Road, Yuelu District, Changsha 410205, China

\begin{abstract}
Background
Increasing success following assisted reproduction technology (ART) has been accompanied by concerns about high rates of multiple pregnancies [1]. Multiple pregnancy increased the risks of obstetric and neonatal complications, including but not limited to miscarriage, pre-eclampsia (PE), prematurity, low birth weight and perinatal mortality $[2,3]$. Single embryo transfer (SET)
\end{abstract} original author(s) and the source, provide a link to the Creative Commons licence, and indicate if changes were made. The images or other third party material in this article are included in the article's Creative Commons licence, unless indicated otherwise in a credit line to the material. If material is not included in the article's Creative Commons licence and your intended use is not permitted by statutory regulation or exceeds the permitted use, you will need to obtain permission directly from the copyright holder. To view a copy of this licence, visit http://creativecommons.org/licenses/by/4.0/. The Creative Commons Public Domain Dedication waiver (http://creativeco mmons.org/publicdomain/zero/1.0/) applies to the data made available in this article, unless otherwise stated in a credit line to the data. 
is recommended to reduce the complications of multiple pregnancies following ART [4]. The American Society for Reproductive Medicine (ASRM) data from 2000 to 2017 shows that the proportion of SET has increased from 5.7 to $64.2 \%$, among ART-conceived infants, meanwhile the percentage of multiple births has decreased from 53.1 to $26.4 \%$, and simultaneous steady decreases in preterm birth and low birth weight rates have also been observed $[5,6]$. However, this potential gain needs to be balanced against the risk of jeopardising the overall live birth rate (LBR). The latest Cochrane meta-analysis based on 12 randomized controlled trials (RCTs) shows that the chance of live birth was reduced in women undergoing SET compared with double embryo transfer (DET), the summarized relative risk (RR) was 0.67 (95\% CI, 0.590.75) [7]. In addition, a large ART cycle dataset indicated that SET for any embryo transfer would result in a one-third lower LBR relative to DET [8]. Beyond these comparisons of overall LBR and multiple pregnancy rate (MPR), the studies did not further refine the population applicability of SET and DET, nor did they comprehensively assess the possible complications. Evidence referring to the trade-offs between live birth and multiple pregnancy following ART are insufficient.

It is well known that many patients idealize that twins would be their optimum outcome following ART [9], therefore DET is likely to remain part of clinical practice for the foreseeable future. The current issue arising is that for which patient cohorts are SET or DET most suited [10]. Due to the homogenous population and limited sample size, existing RCTs [11-24] and aggregated meta-analyses $[4,7]$ comparing the number of embryos transferred do not answer the above question. Clinical practice faces challenges of different patient age, cycles, embryo stages, embryo quality ratings etc., and would benefit from direction regarding which strategy would be most beneficial to specific subgroups. Moreover, although the latest ASRM guidelines have recommended a limit to the number of embryos transferred for different age groups, the evidence for this recommendation has not been disclosed and published [25]. More supporting evidence is therefore needed to assist ART program clinicians and patients.

Large observational studies focusing on the comparisons of different policies regarding the number of embryos transferred are emerging and do provide valid information [26-28]. The diverse population and large sample size offer the possibility of comprehensive subgroup analyses, involving different ages, embryo stages and embryo quality stratification, etc. [26, 29-31]. Additionally, longer follow-up times ensure the observation of reproductive, obstetric and perinatal outcomes. Thus, by integrating the information extracting from RCTs and observational studies, we investigated the overall effectiveness (e.g., LBR and MPR) of SET versus DET, and also focused on (i) whether transferring one or two embryos would be more beneficial to specific subgroups, especially in the consideration of embryo quality and maternal age, and (ii) assessing perinatal and neonatal complications following SET/DET as comprehensively as possible.

\section{Methods}

This systematic review adhered to the PRISMA guidelines [32], and was prospectively registered on PROSPERO (registration ID: CRD42021258452). Institutional review board approval was not required as it was a meta-analysis.

\section{Inclusion criteria}

RCTs and observational studies comparing benefits and risks of SET versus DET in a single cycle, in infertile women using their own oocytes and embryos were deemed eligible for inclusion. To prevent any confusion between per person and per cycle, studies were excluded if it was not possible to clarify that each woman was included only once.

\section{Literature search}

A systematic electronic literature search was performed in PubMed, Embase, Cochrane Library, and RCT registries including ClinicalTrials.gov and WHO International Clinical Trials Registry Platform, through to February 9, 2021. The bibliographies of relevant studies and reviews were scrutinized for any additional eligible studies not covered by the literature search. The literature search combined the terms and descriptors related to human embryo transplantation concerning literature published in English (Supplemental file for full literature search). Conference abstracts and comments were not considered.

\section{Outcome measures}

All the available reproductive, obstetric and perinatal outcomes were measured (Supplemental file for the definition of outcome). Pre-specified primary outcomes were LBR and MPR. The secondary outcomes included clinical pregnancy rate (CPR), miscarriage, birth weight, delivery gestational age, preterm birth, low birth weight, perinatal mortality, birth defect, caesarean section, gestational diabetes (GDM), PE, antepartum haemorrhage $(\mathrm{APH})$, Apgar $1<7$, neonatal intensive care unit (NICU) admission.

\section{Study selection and data extraction}

Citations were merged in Microsoft Access Database to facilitate management. Duplicates were removed, and 
two reviewers independently applied the inclusion criteria to all retrieved citations in an un-blinded standardized manner, screened by title, abstract and full text successively. Data on characteristics of study (first author, publication year, location, study design and study period), population (participants, age, major inclusion and exclusion criteria), cycle (type of cycle, first or not and embryo stage), comparison categories and clinical outcomes (sample size, numbers of events and total, mean, standard deviation, risk estimates, 95\% CIs, adjusted factors and conclusions) were extracted onto a piloted structured form by two reviewers, independently. The most comprehensive report would be given precedence if there were multiple publications from the same study or data source, while the others might be used as supplementary information. When studies had multiple comparisons, only the information and data of interest were extracted. Any uncertainty or disagreements were resolved through discussion and, if necessary, a consensus could be reached with the help of senior authors.

\section{Quality assessment and statistical analysis}

The quality of included RCTs was assessed using the Cochrane risk of bias tool [33]. The Newcastle-Ottawa quality assessment scale (NOS) was used to assess the quality of included observational studies [34]. Comparisons were conducted between SET and DET groups in a single cycle. Considering the inclusion of both RCT and observational studies, meta-analyses were conducted using a Mantel-Haenszel (MH) random-effects model. To assess the possible impact of characteristics of the patients and embryos, subgroup analyses were pre-specified to separate the distinct types of study design (RCT or observational studies), cycle (fresh or frozen), embryo stage (cleavage or blastocyst), embryo quality rating and maternal age. Embryos/blastocysts were classified as good quality (GQE) or non-good quality (PQE) according to the standards established in the respective studies, and the subgroup comparisons were set to transplant a single GQE versus two GQEs (G/GG), a single GQE versus two embryos of mixed quality (GQE + PQE) (G/GP), and a single $\mathrm{PQE}$ versus two PQEs (P/PP). Maternal age was divided into three segments, with cut-offs being 35 and 40 years $(<35,35-40, \geq 40$ years). Moreover, sensitivity analyses pooled of adjusted ORs, limited to first cycle or elective SET (eSET) cycles were performed to assess the robustness of the findings. Pooled effect size was deemed statistically significant at $P<0.05$. Most data were dichotomous, we used the numbers of events in the groups of each study to calculate the ORs with 95\% CIs. For continuous parameters, all the units had been harmonized by data conversion prior to analysis, the weighted mean differences (WMD) with 95\% CIs were pooled to determine the effect size [35]. Heterogeneity was quantified using the estimated $I^{2}$ statistic [36]. Publication bias was assessed using Begg's test for analyses enrolling more than 10 studies [37]. The leave-one-out method was used to evaluate whether any single study dominated the findings. All statistical analyses were performed using $\mathrm{R}$ version 4.1.0.

\section{Results}

\section{Description of included studies}

The literature search retrieved 14,938 citations. After removing duplicates, 11,847 abstracts were reviewed and 1071 full-text articles were further assessed for eligibility. Finally, 85 articles [2, 11-24, 26-31, 38-101] involving 339,492 participants, provided extractable data for the quantitative meta-analysis (Fig. 1), including 14 RCTs and 71 observational studies; of which, data extracted by two RCTs $[14,20]$ came from four references $[14,20$, $63,92]$, and the other two RCT studies [16, 23] provided both the results of RCTs and observational cohorts. The characteristics of the included studies are presented in Supplementary Table S1. Women from 24 studies were recruited during their first cycle and 44 studies provided data on eSET. Most studies clarified the type of cycles (69 fresh, 11 frozen and 5 both) and the stage of embryo transfer (34 cleavage, 24 blastocyst, 23 both and 4 unclear). Thirteen studies provided results of stratified comparison based on embryo quality (12G/GG, 11G/ GP and $8 \mathrm{P} / \mathrm{PP}$ ), and 22 studies were included in the subanalyses considering different age groups (17 aged $<35$, 6 aged $35-40$ and 5 aged $\geq 40$ years). The results of quality assessment are presented in Supplementary Table S2. Twelve RCTs reported a randomization method, five carried out allocation concealment and six executed blinding for participants or personnel. Nine observational studies were awarded six stars in quality assessment, 47 studies were graded seven stars and 15 studies were marked eight stars.

\section{Primary outcomes Live birth rate}

Sixty-two studies $[11-20,22-24, \quad 26-31, \quad 38-41$, $44,45,47-53,56,58,60-62,64-66,69,71,73-75$, 77-84, 86-91, 94, 99] demonstrated a reduced LBR after SET $(28,529 / 85,988,33.2 \%)$ than that after DET $(113,658 / 247,116,46.0 \%)$ in a single cycle $(O R=0.78$, 95\% CI: $0.71-0.85, I^{2}=91 \%, P<0.001$ ) (Supplementary Fig. S1). The analysis results are presented in Table 1 . No publication bias was detected by Begg's test $(P=0.062)$.

Among subgroup analyses, when considering different age groups of included patients, an increase in LBR favoring the DET group was noted for patients aged $<35$ years $\left(0.71, \quad 0.61-0.84, \quad I^{2}=85 \%, \quad n=12\right)$ and $35-40$ years 


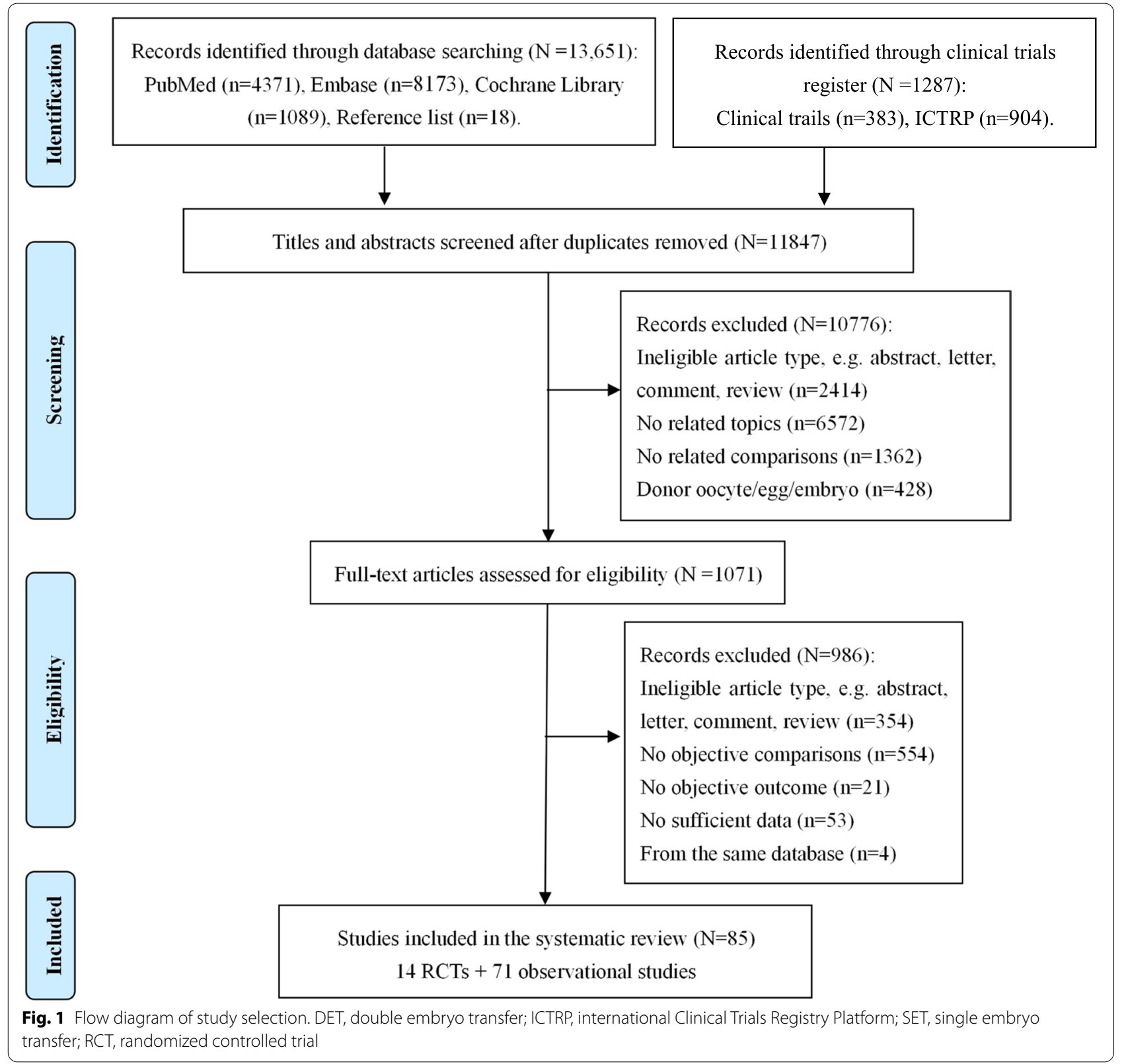

(0.80, 0.69-0.94, $\left.I^{2}=69 \%, n=6\right)$, but no difference was observed for patients $\geq 40$ years old $(0.87,0.54-1.40$, $I^{2}=69 \%, P=0.565, n=4$; Fig. 2). The difference in the comparison of LBR between groups decreased with age stratification. When considering embryo quality, the LBR was significantly decreased after transferring a single good quality embryo (GQE) compared with two GQEs $\left(0.63,0.52-0.77, I^{2}=82 \%, n=7\right)$, as well as a single PQE compared with two PQEs (0.57, 0.45-0.71, $I^{2}=0 \%, n=3$; Fig. 2). Meanwhile, no difference was noted between a single GQE and two embryos of mixed quality $(\mathrm{GQE}+\mathrm{PQE})\left(0.99,0.77-1.27, I^{2}=81 \%, P=0.915\right.$, $n=8$; Fig. 2). Subgroup analyses performed according to embryo stage (cleavage, blastocyst) and cycle type (fresh, frozen) suggested that, the chance of live birth in the DET group was significantly greater than that in the SET group in all the subgroups, with ORs being 0.67 $(P<0.001, n=32), 0.81(P=0.001, n=25), 0.80(P<0.001$, $n=53)$ and $0.74(P=0.013, n=10)$, respectively. Subanalysis concerning study design indicated that the combination of RCTs resulted in a lower OR $(0.53,0.44-0.63$, $\left.I^{2}=0 \%, n=13\right)$, compared with the result obtained from observational studies $\left(0.82,0.75-0.90, I^{2}=93 \%, n=49, P\right.$ for interaction $<0.001)$. 


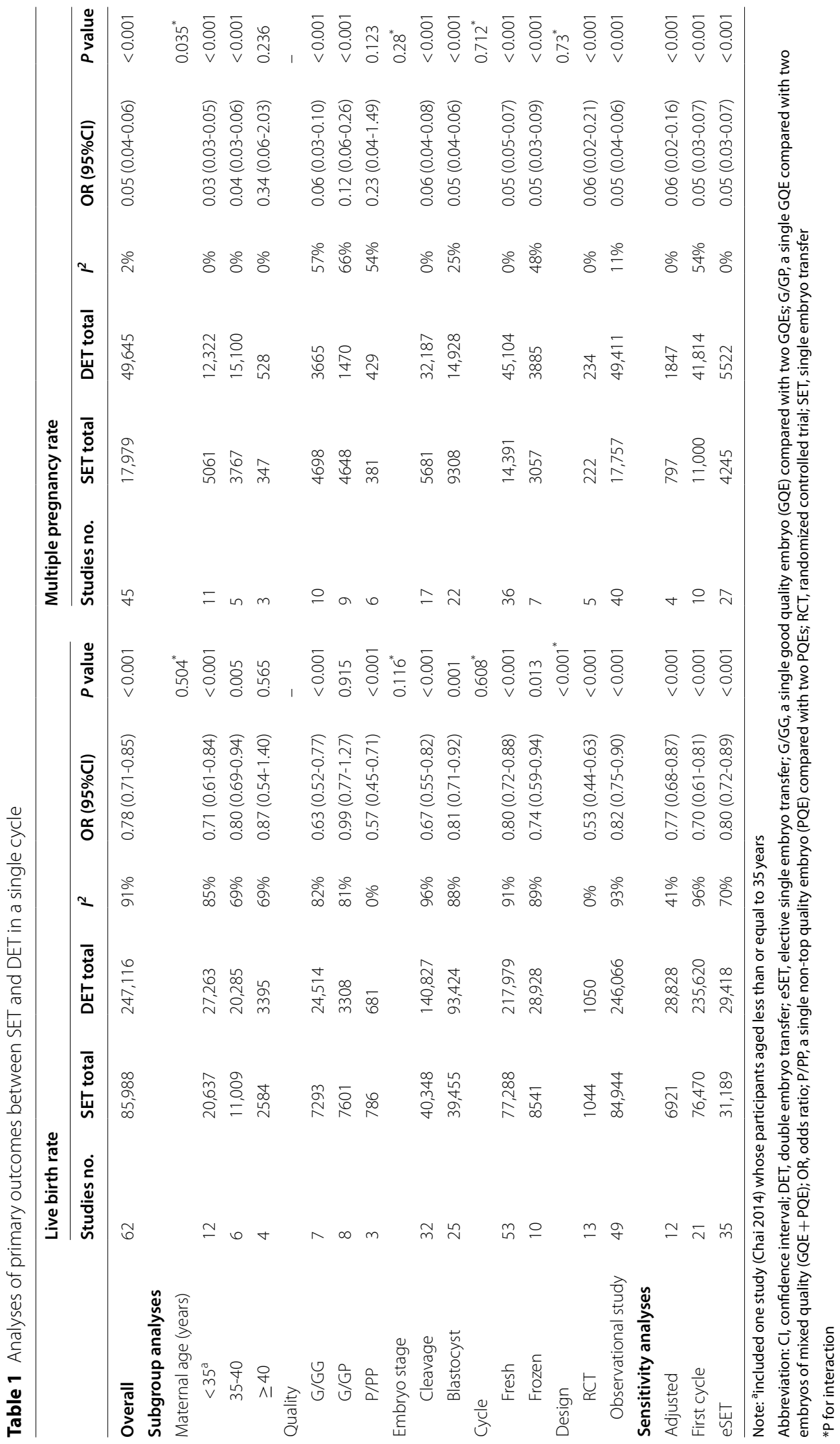




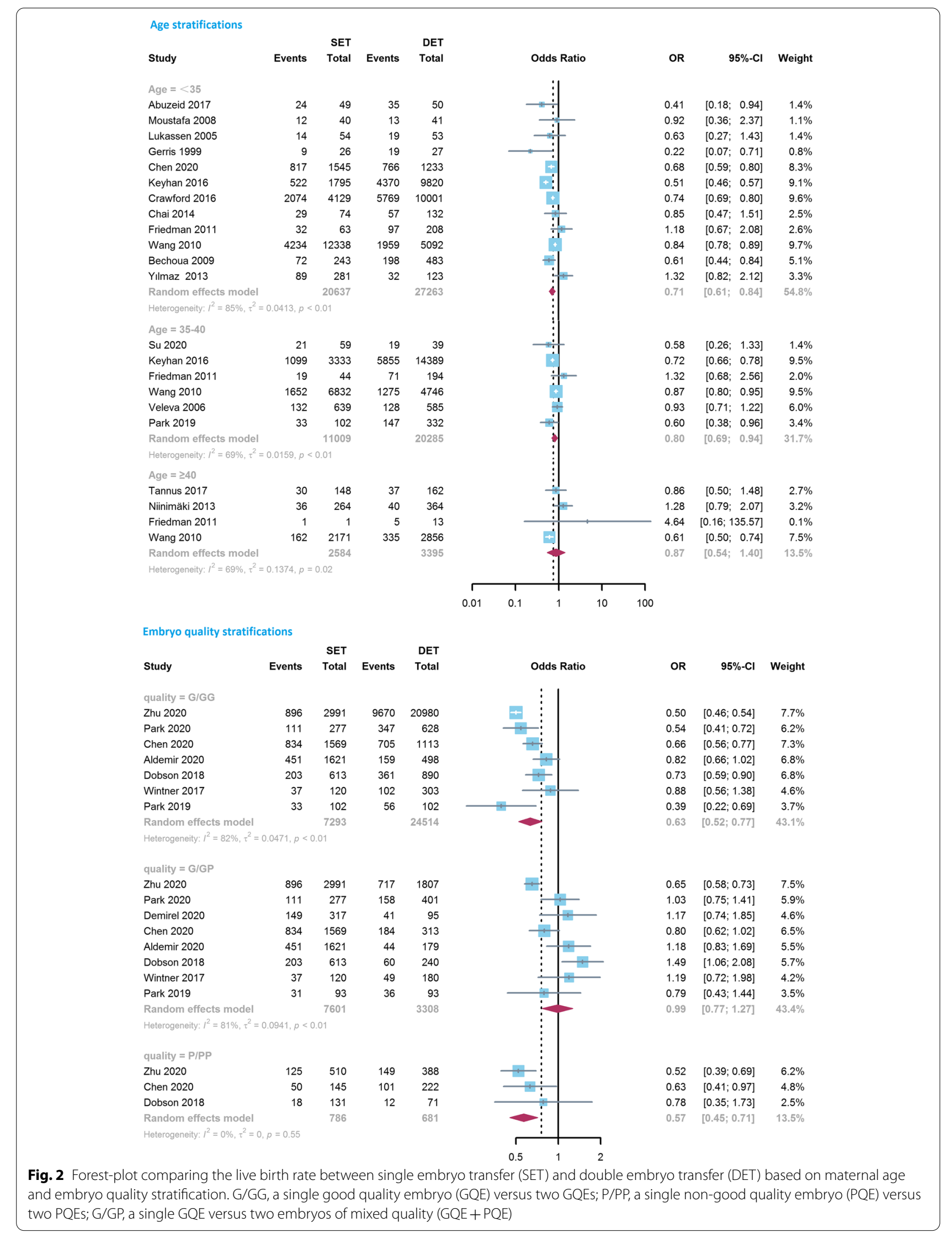




\section{Multiple pregnancy rate}

Forty-five studies $[2,11,13,15,21,24,28-31,38,39,43$, $44,48-50,53,54,56-59,62,64,66-69,72,75-77,79-81$, 85-87, 91, 93-96, 98] were pooled and found that the MPR was significantly lower in the SET group than in the DET group $\left(0.05,0.04-0.06, I^{2}=2 \%, P<0.001\right)$ (Supplementary Fig. S2). This suggested that for a woman with a $16.7 \%(8314 / 49,645)$ chance of multiple pregnancy following a single cycle of DET, the rate following a single SET would be between 0.7 and $1.0 \%$. The analysis results are presented in Table 1 . No publication bias was detected by Begg's test $(P=0.531)$.

In the subgroup analyses of age stratification (Fig. 3), the differences of MPR between SET and DET were stable and significant in women aged $<35(0.03,0.03-$ $\left.0.05, I^{2}=0 \%, P<0.001, n=11\right)$ and $35-40$ years $(0.04$, $\left.0.03-0.06, I^{2}=0 \%, P<0.001, n=5\right)$, whereas the aggregate result from three studies found that the difference became insignificant in patients aged $\geq 40$ years $(0.34$, $\left.0.06-2.03, I^{2}=0 \%, P=0.236, n=3\right)$. Similarly, 10 observational studies investigated the differences in the association between MPR and the number of transferred embryos by embryo quality grade (Fig. 3). In comparison with a single GQE, transferring two GQEs and two embryos of mixed quality (GQE + PQE) both led to significantly higher MPRs, the ORs were $0.06(0.03-0.10$, $\left.I^{2}=57 \%, P<0.001, n=10\right)$ and $0.12\left(0.06-0.26, I^{2}=66 \%\right.$, $P<0.001, n=9)$, respectively. However, the difference in MPR between a single PQE and two PQEs was reduced and was no longer be statistically significant $(0.23,0.04-$ $\left.1.49, I^{2}=54 \%, P=0.123, n=6\right)$. Moreover, the pooled results did not materially change in the subgroup analyses regarding embryo stage (cleavage, blastocyst), cycle type (fresh, frozen) and study design (RCT, observational study), with pooled ORs being $0.05(P<0.001)$ or 0.06 $(P<0.001)$.

\section{Secondary Outcomes}

Table 2 summarizes the overall analysis results of secondary maternal pregnancy outcomes and neonatal outcomes.

A significant decrease in CPR (37.4\% vs. $48.0 \%, 0.78$, $\left.0.71-0.85, I^{2}=82 \%, P<0.001, n=60\right)$ was noted in the SET group compared with the DET group [11-15, 19, 23, $24,27-31,38,39,41-44,48-51,53-59,62,64-67,69$, 70, 72, 74-81, 84, 86, 87, 90, 91, 93-98, 100, 101]. Several subgroup analyses indicated a different direction, no differences of CPR were noted between SET and DET in subgroups of patients aged $\geq 40$ years $(0.88,0.59-1.30$, $\left.I^{2}=70 \%, n=5\right)$, GQE versus GQE + PQE (1.01, 0.89$\left.1.16, I^{2}=0 \%, n=9\right)$, and frozen cycles $(0.79,0.62-1.00$, $I^{2}=83 \%, n=9$; Supplementary Table S3, Fig. S3). Fortythree studies $[11-14,16,19,20,23,28-31,38-44,48$,
$50,51,53,55,57,58,62,64-66,69,72,74,77,79-81$, $90,91,94,95,98]$ evaluated the miscarriage rates, and no significant difference was found between groups during the overall analysis (15.6\% vs. $14.2 \%, 1.10,0.95-1.27$, $\left.I^{2}=30 \%, P=0.211\right)$, neither in all the conducted subgroups (Supplementary Table S4). Seven studies [19, $30,39,58,65,81,94$ ] provided information on perinatal mortality, and no difference was observed $(0.3 \%$ vs $\left.0.7 \%, 0.71,0.25-2.06, I^{2}=0 \%, P=0.532\right)$. Compared with DET, mothers with SET had a lower risk of cesarean section $\left(0.64,0.43-0.94, I^{2}=15 \%, P=0.024, n=3\right)$. Only one included study [39] reported on GDM, PE and $\mathrm{APH}$ in the late pregnancy, there was no significant difference between SET and DET groups with respect to the risk of GDM $(0.0 \%$ vs. $1.0 \%, P=0.623)$ and $\mathrm{PE}(3.9 \%$ vs. $0.0 \%, P=0.132$ ), meanwhile, APH rate was significantly lower in the SET group (10.5\% vs. $25.2 \%, 0.35,0.15-0.82$, $P=0.016)$.

Eight studies [11, 15, 29, 30, 44, 53, 65, 81], including 2907 live birth cycles, provided data on continuous gestational age at birth. A significantly longer gestational age at birth was found in the SET group compared with the DET group (WMD $=0.88$ weeks, 95\% CI: $0.56-1.20$, $\left.I^{2}=58 \%, P<0.001\right)$. Moreover, 13 studies $[11,19,23,29-$ $31,38,39,44,53,65,77,81]$ evaluated preterm birth, and a significantly reduced probability of preterm birth was observed in the SET group (9.9\% vs. 31\%, 0.25, 0.21-0.30, $\left.I^{2}=0 \%, P<0.001\right)$. The overall findings did not materially change in all the conducted subgroup analyses (Supplementary Table S5). Similarly, the overall birth weight of live births in the SET group was significantly higher than that in the DET group in a single cycle (WMD $=297.47 \mathrm{~g}$, 95\% CI: $\left.208.47-386.46, \mathrm{I}^{2}=84 \%, P<0.001, n=7\right)$. The pooled analysis of low birth weight rate generated a total of 3962 live births from nine studies [19, 23, 29, 30, 38, 39, $44,77,81$ ], and revealed a significant decrease in risk of low birth weight in the SET group (7.6\% vs. $28.9 \%, 0.20$, $\left.0.16-0.25, \mathrm{I}^{2}=0 \%, P<0.001\right)$, the finding was further confirmed by all the conducted subgroup analyses (Supplementary Table S6). Aggregated data from three studies $[30,44,53]$ showed that there was no statistical difference in the risk of birth defects between groups (1.6\% vs. $1.3 \%, P=0.414)$, while two other studies $[39,81]$ reported statistically different risks of Apgar $1<7$ rate $(0.0 \%$ vs. $\left.7.8 \%, 0.12,0.02-0.93, I^{2}=0 \%, P=0.042, n=2\right)$ and NICU admission rate $\left(8.1 \%\right.$ vs. $23.8 \%, 0.30,0.14-0.66, I^{2}=0 \%$, $P=0.003, n=2)$.

\section{Sensitivity Analyses}

For the comparison of LBR, sensitivity analyses pooled of adjusted ORs $(0.77,0.68-0.87, P<0.001, n=12)$, limited to first cycle $(0.70,0.61-0.81, P<0.001, n=21)$ and eSET cycles $(0.80,0.72-0.89, P<0.001, n=35)$ confirmed 


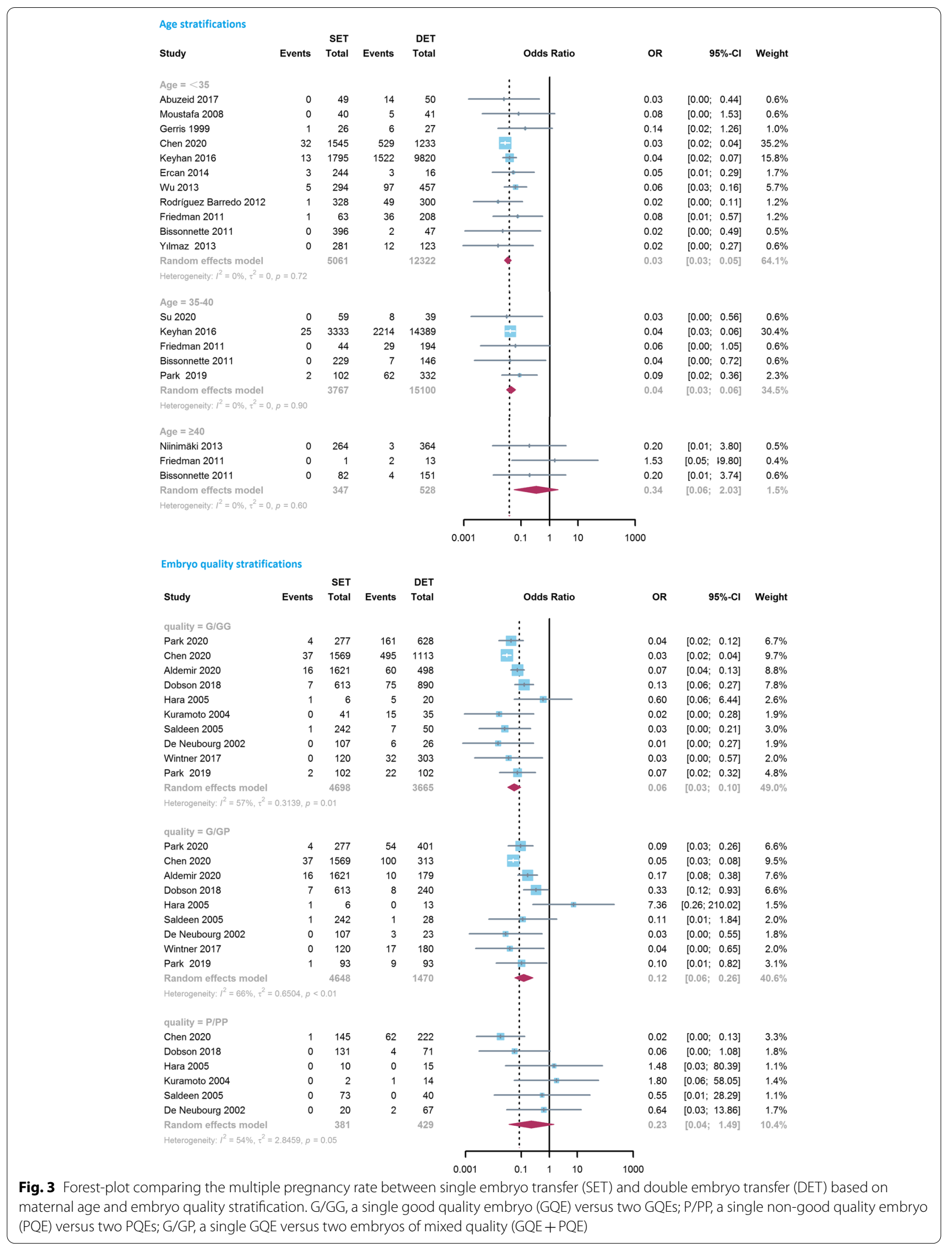


Table 2 Overall analyses of secondary outcomes between SET and DET in a single cycle

\begin{tabular}{|c|c|c|c|c|c|c|}
\hline Index & Studies no. & SET total & DET total & $1^{2}$ & OR/WMD (95\%Cl) & $P$ value \\
\hline \multicolumn{7}{|c|}{ Maternal pregnancy outcomes and complications } \\
\hline CPR & 60 & 43,414 & 68,289 & $82 \%$ & $0.78(0.71-0.85)$ & $<0.001$ \\
\hline Miscarriage rate & 43 & 5230 & 13,249 & $30 \%$ & $1.10(0.95-1.27)$ & 0.211 \\
\hline Perinatal mortality rate & 7 & 1135 & 1970 & $0 \%$ & $0.71(0.25-2.06)$ & 0.532 \\
\hline Cesarean rate & 3 & 238 & 698 & $15 \%$ & $0.64(0.43-0.94)$ & 0.024 \\
\hline GDM rate & 1 & 76 & 103 & - & $0.45(0.02-11.11)$ & 0.623 \\
\hline PE rate & 1 & 76 & 103 & - & $9.86(0.50-193.72)$ & 0.132 \\
\hline APH rate & 1 & 76 & 103 & - & $0.35(0.15-0.82)$ & 0.016 \\
\hline \multicolumn{7}{|c|}{ Neonatal outcomes and complications } \\
\hline Delivery gestational age (week) & 8 & 1136 & 1771 & $58 \%$ & $0.88(0.56-1.20)$ & $<0.001$ \\
\hline Preterm birth rate ${ }^{a}$ & 13 & 1852 & 2380 & $0 \%$ & $0.25(0.21-0.30)$ & $<0.001$ \\
\hline Birth weight (g) & 7 & 1164 & 2572 & $84 \%$ & $297.47(208.47-386.46)$ & $<0.001$ \\
\hline Low birth weight rate & 9 & 1360 & 2826 & $0 \%$ & $0.20(0.16-0.25)$ & $<0.001$ \\
\hline Birth defect rate & 3 & 964 & 1672 & $0 \%$ & $1.32(0.68-2.59)$ & 0.414 \\
\hline Apgar $1<7$ rate & 2 & 99 & 193 & $0 \%$ & $0.12(0.02-0.93)$ & 0.042 \\
\hline NICU admission rate & 2 & 99 & 193 & $0 \%$ & $0.30(0.14-0.66)$ & 0.003 \\
\hline
\end{tabular}

Note: apreterm birth rate was calculated as the number of preterm births divided by the total number of live births (multiple gestations included) in one of included studies (Sini 2020)

Abbreviation: 2SET Two consecutive elective single embryo transfer; $A P H$ Antepartum haemorrhage; $C$ Confidence interval; $C P R$ Clinical pregnancy rate; DET Double embryo transfer; GDM Gestational diabetes; LBR Live birth rate; MBR Multiple birth rate; MPR Multiple pregnancy rate; NICU Neonatal intensive care unit; OR Odds ratio; PE Pre-eclampsia; WMD Weighted mean difference

the stability of the overall result (Table 1). The compared results of MPR were robust in all the pre-specified sensitivity analyses, with pooled ORs being 0.05 or 0.06 $(P<0.001$; Table 1). No difference of CPR was noted between SET and DET in the summary of adjusted ORs $(0.85,0.61-1.18, P=0.326, n=6)$, while the sensitivity analyses limited to first cycle $(0.68,0.57-0.80, P<0.001$, $n=14)$ and eSET cycles $(0.82,0.73-0.92, P=0.001$, $n=35$ ) confirmed the stability of the overall result (Supplementary Table S3). Similarly, except that a significantly higher risk of miscarriage was found in the SET group when the included studies were restricted to the first cycle $(1.43,1.10-1.86, P=0.009, n=10)$, no differences were found in all the other sensitivity analyses (Supplementary Table S4). Additionally, both the compared results of preterm birth rate and low birth weight rate were robust in all the pre-specified sensitivity analyses (Supplementary Table S5, 6).

\section{Discussion}

This systematic review is the most complete assessment of the short-term and long-term outcomes of SET versus DET to date. The findings of overall effectiveness (e.g., LBR and MPR) of SET versus DET were consistent with current evidence. SET yielded less probability of a live birth $(0.78,0.71-0.85)$ than DET in a single cycle, while simultaneously reducing the rate of multiple gestation $(0.05,0.04-0.06)$. By contrast, the present study provided more comprehensive subgroup/sensitivity analyses and tracked more adverse fertility outcomes, further promoted the generation of individual program. Interestingly, changes emerged during several subgroup comparisons.

An important factor that needs to be considered during embryo transfer is maternal age, particularly given the age-dependent decrements in ovarian function [102]. Recruitment data indicated that the effect sizes of LBR and CPR between SET and DET groups gradually increased with increasing age. The increased benefit of a live birth, as well as a decreased rate of multiple pregnancy, favoring the DET group, were noted for patients aged $<35$ years $(0.71,0.61-0.84 ; 0.03,0.03-0.05)$ and $35-40$ years $(0.80,0.69-0.94 ; 0.04,0.03-0.06)$. At age $\geq 40$ years, the differences in LBR $(0.87,0.54-1.40)$ and MPR $(0.34,0.06-2.03)$ between the groups were no longer statistically significant. The findings suggested that women $<40$ years, including those aged 35-40years, may have a lower possibility of multiple pregnancy after choosing SET. However, for elderly women $\geq 40$ years old, current evidence is insufficient to recommend an appropriate number of embryos to be transferred. Knowing that older women would suffer greater rates of oocyte aneuploidy and a decline in uterine receptivity [8], women of advanced age are most likely to have multiple embryos transferred as recommended by the ASRM guidelines [25]. There are discrepancies between 
the current results and the recommendations of the guidelines [25] in terms of the recommended number of embryos to be transferred in women $\geq 35$ years. There is still an argument to be made in favor of SET or DET in these certain situations, the choice must be jointly made by patients and physicians based on the patients' desires, the individual's chances of a twin pregnancy and success [103]. More researches need to be devoted to the research in advanced-age infertile women, taking into account the impact of age on reproductive function and that advancing age also leads to a greater risk of adverse pregnancy outcomes [104].

Regarding embryo quality, compared with two GQEs, transferring a single GQE gained a significantly lower possibility of multiple pregnancy $(0.06,0.03-0.10)$, as well as a lower rate of live birth $(0.63,0.52-0.77)$. Since the chance of a live birth after a single PQE was only about $57 \%$ of that achieved by two PQEs, and there was no statistical difference in the MPR between groups, choosing to the DET might be beneficial in the absence of GQEs. The comparison between a single GQE and two embryos of GQE + PQE indicated that the PQE along with GQE did not improve the effectiveness of transfer, but significantly increased the risks of perinatal complications, including MPR, preterm birth rate and low birth weight rate. The interaction was proposed to explain that pre-implantation embryos could affect the development of surrounding embryos through the release of specific growth factors $[105,106]$. Moreover, our sensitivity analyses showed that, despite the same effect size of MPR, eSET produced a slightly reduced difference in LBR between groups, and the ratio was $80 \%$ of the DET group, this is perhaps an acceptable LBR on the premise that the MPR could be dramatically reduced. Thus, eSET/SET is recommended when there is one or more GQE, this is consistent with the ASRM guidelines, which recommend SET in cases where a euploid embryo is available [25].

With the apparent shift in the goal of ART, favorable perinatal outcomes have been regarded as crucial as a successful clinical pregnancy [39]. Compared with previously published meta-analyses $[4,7]$, in addition to the benefits, this study tracked more perinatal and neonatal complications following SET/DET. The findings showed that both the mothers and infants conceived through SET acquired reduced risks of poor outcomes, verified through the lower rates of cesarean section $(0.64,0.43-0.94)$, APH $(0.35,0.15-0.82)$, preterm birth $(0.25,0.21-0.30)$, low birth weight $(0.20,0.16-0.25)$, Apgar $1<7$ rate $(0.12,0.02$ $0.93)$ and NICU admission (0.30, 0.14-0.66). These were justified by similar findings of other studies [107-109]. As multiple pregnancy has been greatly associated with the above complications, the reduction of its incidence in ART cycles using SET might have contributed to the favorable perinatal and neonatal outcomes. In addition to the negative influences on perinatal outcomes, multiple pregnancy could also adversely impact the infant's first year of life and potentially increase healthcare needs and cost of living throughout the neonatal period up to the age of 1 year [110]. These longer-term outcomes still need to be further tracked and studied, to provide a more complete evaluation and recommendations.

The strength of this study is the big data from observational researches enabled us to address concerns about the generalizability of data from RCTs to routine clinical care [111]. Additionally, we required that each woman was included only once in each included study, as the inclusion of all ART data with multiple cycles would have introduced statistical complexity as well as concern for potential bias [112]. However, several limitations of this study need to be addressed and merit further discussion. First, although multiple sensitivity and subgroup analyses were carried out, significant heterogeneity existed in some analyses. Second, many observational studies do not report the relative effects of adjustment, so we would only use unadjusted data for the main analyses, however, when we used the adjusted outcomes as sensitivity analyses, most of the results were consistent with the main analyses. Nevertheless, our aggregate data lacked information available to adjust some important confounding factors (such as reason for infertility, medical conditions etc.). Third, the problem of insufficient sample size existed in some of our results, such as the comparisons of GDM rate, PE rate, APH rate and NICU admission rate etc., the relatively small sample size may have limited the power to identify a real difference, which therefore requires cautious interpretation.

\section{Conclusions}

In conclusion, based on the current evidence, SET yielded less probability of a live birth than DET in a single cycle, while simultaneously reducing the possibility of multiple gestation, as well as its related perinatal and neonatal complications. Subgroup analyses suggested that in women $<40$ years old or any GQE is available, SET should be incorporated into clinical practice owing to the significant reduction in MPR and the acceptable LBR. Meanwhile, in the absence of GQEs, DET may be a preferable option because of the significant benefit of a live birth and the insignificant chance of multiple pregnancy. However, for elderly women $\geq 40$ years old, current evidence is insufficient to recommend an appropriate number of embryos to transfer. Further high-quality RCTs or national registry-based cohort studies are still required to confirm these findings that will allow individualized transplantation strategies for different cohorts of infertile women. 


\section{Abbreviations}

ART: Assisted reproduction technology; APH: Antepartum haemorrhage; ASRM: The American Society for Reproductive Medicine; Cl: Confidence interval; CPR: Clinical pregnancy rate; DET: Double embryo transfer; GDM: Gestational diabetes; GQE: Good quality embryos/blastocysts; LBR: Live birth rate; MPR: Multiple pregnancy rate; NICU: Neonatal intensive care unit; NOS: The Newcastle-Ottawa quality assessment scale; OR: Odds ratio; PE: Pre-eclampsia; PQE: Non-good quality embryos/blastocysts; RCT: Randomized controlled trial; RR: Relative risk; SET: Single embryo transfer; WMD: Weighted mean difference.

\section{Supplementary Information}

The online version contains supplementary material available at https://doi. org/10.1186/s12958-022-00899-1.

\section{Additional file 1. \\ Additional file 2: Supplementary Table S1. The characteristics of the included studies. Supplementary Table S2. Methodological quality of included studies. Supplementary Table S3. Sensitivity and subgroup analyses comparing clinical pregnancy rate after SET and DET in a single cycle. Supplementary Table S4. Sensitivity and subgroup analyses comparing miscarriage rate after SET and DET in a single cycle. Supple- mentary Table S5. Sensitivity and subgroup analyses comparing preterm birth rate after SET and DET in a single cycle. Supplementary Table S6. Sensitivity and subgroup analyses comparing low birth weight rate after SET and DET in a single cycle.}

Additional file 3: Figure S1. Forest-plot comparing live birth rate after single embryo transfer (SET) and double embryo transfer (DET) in a single cycle.

Additional file 4: Figure S2. Forest-plot comparing multiple pregnancy rate after single embryo transfer (SET) and double embryo transfer (DET) in a single cycle.

Additional file 5: Figure S3. Forest-plot comparing the clinical pregnancy rate between single embryo transfer (SET) and double embryo transfer (DET) based on maternal age and embryo quality stratification. G/ GG, a single good quality embryo (GQE) versus two GQEs; P/PP, a single non-good quality embryo (PQE) versus two PQEs; G/GP, a single GQE versus two embryos of mixed quality (GQE +PQE).

\section{Acknowledgements}

Not applicable.

\section{Authors' contributions}

Study concept and design: S.M., Y.P. and J.T. Acquisition, analysis, or interpretation of data: S.M., Y.P., X.W., Y.X. and Y.T. Statistical analysis: S.M. Y.P. and Y.X. Drafting of the manuscript: S.M. and Y.P. Critical revision of the manuscript for important intellectual content: L.H. J.T. and F.G. Obtained funding: Y.T. and F.G. Administrative, technical, or material support: J.T. and F.G. Study supervision: J.T. and F.G. All authors read and approved the final manuscript.

\section{Funding}

This study was funded by National Key Research and Development Program of China (2016YFC1000206) and Hunan Provincial Grant for Innovative Province Construction (2019SK4012).

\section{Availability of data and materials}

All data generated or analyzed during this study are included in this published article and its supplementary information files.

\section{Declarations}

Ethics approval and consent to participate

Not applicable.

\section{Consent for publication}

Not applicable.

\section{Competing interests}

The authors declare that they have no competing interests.

Received: 18 November 2021 Accepted: 18 January 2022

Published online: 27 January 2022

\section{References}

1. Bergh C. Single embryo transfer: a mini-review. Hum Reprod. 2005;20:323-7.

2. Neubourg DD, Mangelschots K, Van Royen E, Vercruyssen M, Ryckaert $G$, Valkenburg M, et al. Impact of patients' choice for single embryo transfer of a top quality embryo versus double embryo transfer in the first IVF/ICSI cycle. Hum Reprod. 2002;17:2621-5.

3. The ESHRE Capri Workshop Group. Multiple gestation pregnancy. Hum Reprod. 2000;15:1856-64.

4. McLernon DJ, Harrild K, Bergh C, Davies MJ, de Neubourg D, Dumoulin $J$, et al. Clinical effectiveness of elective single versus double embryo transfer: meta-analysis of individual patient data from randomised trials. BMJ. 2010;341:c6945.

5. Sunderam S, Kissin DM, Zhang Y, Jewett A, Boulet SL, Warner L, et al. Assisted Reproductive Technology Surveillance - United States, 2017. MMWR Surveill Summ. 2020;69:1-20.

6. Wright VC, Schieve LA, Reynolds MA, Jeng G. Assisted reproductive technology surveillance--United States, 2000. MMWR Surveill Summ. 2003;52:1-16

7. Kamath MS, Mascarenhas M, Kirubakaran R, Bhattacharya S. Number of embryos for transfer following in vitro fertilisation or intra- cytoplasmic sperm injection. Cochrane Database Syst Rev. 2020;8:Cd003416.

8. Roberts SA, McGowan L, Mark Hirst W, Vail A, Rutherford A, Lieberman BA, et al. Reducing the incidence of twins from IVF treatments: predictive modelling from a retrospective cohort. Hum Reprod. 2011;26:569-75.

9. Cutting R. Single embryo transfer for all. Best Pract Res Clin Obstet Gynaecol. 2018;53:30-7.

10. Harbottle S, Hughes C, Cutting R, Roberts S, Brison D. Elective Single Embryo Transfer: an update to UK Best Practice Guidelines. Hum Fertil (Camb). 2015;18:165-83.

11. Abuzeid OM, Deanna J, Abdelaziz A, Joseph SK, Abuzeid YM, Salem WH, et al. The impact of single versus double blastocyst transfer on pregnancy outcomes: A prospective, randomized control trial. Facts Views Vis Obgyn. 2017;9:195-206.

12. Prados N, Quiroga R, Caligara C, Ruiz M, Blasco V, Pellicer A, et al. Elective single versus double embryo transfer: Live birth outcome and patient acceptance in a prospective randomised trial. Reprod Fertil Dev. 2015;27:794-800.

13. López-Regalado ML, Clavero A, Gonzalvo MC, Serrano M, Martínez L, Mozas J, et al. Randomised clinical trial comparing elective singleembryo transfer followed by single-embryo cryotransfer versus double embryo transfer. Eur J Obstet Gynecol Reprod Biol. 2014;178:192-8.

14. Forman EJ, Hong KH, Ferry KM, Tao X, Taylor D, Levy B, et al. In vitro fertilization with single euploid blastocyst transfer: a randomized controlled trial. Fertil Steril. 2013;100:100-7.e1.

15. Moustafa MK, Sheded SA, El Aziz Mousta MA. Elective single embryo transfer versus double embryo transfer in assisted reproduction. Reprod BioMed Online. 2008;17:82-7.

16. van Montfoort AP, Fiddelers AA, Janssen JM, Derhaag JG, Dirksen CD, Dunselman GA, et al. In unselected patients, elective single embryo transfer prevents all multiples, but results in significantly lower pregnancy rates compared with double embryo transfer: a randomized controlled trial. Hum Reprod. 2006;21:338-43.

17. Bhattacharya S: ISRCTN86466058. Elicacy and Cost Electiveness of Selective Single Embryo transfer [Elicacy and cost electiveness of selective single embryo transfer: a multi-centre randomised controlled trial]. Reference Cochrane Review (Pandian 2020) 20 Mar 2021. 2006.

18. Thurin A: Elective single embryo transfer [Doctoral thesis]. Gothenburg (Sweden): University of Gothenburg. Reference Cochrane Review (Pandian 2020) 20 Mar 2021. 2005.

19. Lukassen HGM, Braat DD, Wetzels AMM, Zielhuis GA, Adang EMM, Scheenjes $\mathrm{E}$, et al. Two cycles with single embryo transfer versus one cycle with double embryo transfer: A randomized controlled trial. Hum Reprod. 2005;20:702-8. 
20. Thurin A, Hausken J, Hillensjö T, Jablonowska B, Pinborg A, Strandell A, et al. Elective single-embryo transfer versus double-embryo transfer in in vitro fertilization. N Engl J Med. 2004;351:2392-402.

21. Gardner DK, Surrey E, Minjarez D, Leitz A, Stevens J, Schoolcraft WB. Single blastocyst transfer: a prospective randomized trial. Fertil Steril. 2004;81:551-5.

22. Davies M: Australian Study of Single Embryo Transfer (ASSET) clinical protocol. A multi-centre double blind randomised controlled trial to compare the outcomes of pregnancy following the transfer of either a single embryo (SET) or two embryos (DET) in an optimal group of patients undergoing in-vitro fertilization (IVF) with or without intracytoplasmic sperm injection (ICSI) 2003.

23. Martikainen $\mathrm{H}$, Tiitinen A, Tomás C, Tapanainen J, Orava M, Tuomivaara $L$, et al. One versus two embryo transfer after IVF and ICSI: a randomized study. Hum Reprod. 2001;16:1900-3.

24. Gerris J, De Neubourg D, Mangelschots K, Van Royen E, Van de Meerssche M, Valkenburg M. Prevention of twin pregnancy after invitro fertilization or intracytoplasmic sperm injection based on strict embryo criteria: a prospective randomized clinical trial. Hum Reprod. 1999;14:2581-7.

25. Medicine PCotASfR. Guidance on the limits to the number of embryos to transfer: a committee opinion. Fertil Steril. 2017;107:901-3.

26. Zhu Q, Lin J, Gao H, Wang N, Wang B, Wang Y. The Association Between Embryo Quality, Number of Transferred Embryos and Live Birth Rate After Vitrified Cleavage-Stage Embryos and Blastocyst Transfer. Front Physiol. 2020;11:930

27. Racca A, Drakopoulos P, Van Landuyt L, Willem C, Santos-Ribeiro S, Tournaye $H$, et al. Single and double embryo transfer provide similar live birth rates in frozen cycles. Gynecol Endocrinol. 2020;36:824-8.

28. Jin HX, Lv AX, Wu ZT, Wen S, Zhang XY, Jin DC, et al. Comparative study on the pregnancy outcomes of in vitro fertilization-embryo transfer between patients with different ovarian responses (a STROBE-compliant article). Medicine (Baltimore). 2019;98:e16191.

29. Park DS, Kim JW, Eum JH, Lee WS, Yoon TK, Lyu SW. Clinical and preg nancy outcomes of double and single blastocyst transfers related with morphological grades in vitrified-warmed embryo transfer. Taiwan J Obstet Gynecol. 2020;59:398-402.

30. Chen S, Du H, Liu J, Liu H, Li L, He Y. Live birth rate and neonatal outcomes of different quantities and qualities of frozen transferred blastocyst in patients requiring whole embryo freezing stratified by age. BMC Pregnancy Childbirth. 2020;20(1):655.

31. Aldemir O, Ozelci R, Baser E, Kaplanoglu I, Dilbaz S, Dilbaz B, et al. Impact of Transferring a Poor Quality Embryo along with a Good Quality Embryo on Pregnancy Outcomes in IVF/ICSI Cycles: a Retrospective Study. Geburtshilfe Frauenheilkd. 2020;80:844-50.

32. Shamseer L, Moher D, Clarke M, Ghersi D, Liberati A, Petticrew M, et al. Preferred reporting items for systematic review and metaanalysis protocols (PRISMA-P) 2015: elaboration and explanation. BMJ. 2015;350:g7647.

33. Higgins JP, Altman DG. Assessing risk of bias in included studies Cochrane handbook for systematic reviews of interventions Wiley; 2008, Chapter 8. p. 187-241.

34. Stang A. Critical evaluation of the Newcastle-Ottawa scale for the assessment of the quality of nonrandomized studies in meta-analyses. Eur J Epidemiol. 2010;25:603-5.

35. Takeshima N, Sozu T, Tajika A, Ogawa Y, Hayasaka Y, Furukawa TA. Which is more generalizable, powerful and interpretable in meta-analyses, mean difference or standardized mean difference? BMC Med Res Methodol. 2014;14:30.

36. Higgins JP, Thompson SG, Deeks JJ, Altman DG. Measuring inconsistency in meta-analyses. BMJ. 2003;327:557-60.

37. Begg CB, Mazumdar M. Operating characteristics of a rank correlation test for publication bias. Biometrics. 1994;50:1088-101.

38. Su W, Xu J, Arhin SK, Liu C, Zhao J, Lu X. The Feasibility of All-BlastocystCulture and Single Blastocyst Transfer Strategy in Elderly Women: A Retrospective Analysis. Biomed Res Int. 2020;2020:5634147.

39. Sini I, Handayani N, Pratiwi A, Polim A, Boediono A. Blastocyst elective single embryo transfer improves perinatal outcomes among women undergoing assisted reproductive technology in Indonesia. Asian Pac J Reprod. 2020;9:118-23.

40. Demirel C, Goksever Celik H, Tulek F, Tuysuz G, Donmez E, Ergin T, et al. The impact of a poor quality embryo on the implantation chance of a good quality one when transferred together: A study on double blastocyst transfers. J Gynecol Obstet Hum Reprod. 2020;5:101967. https:// doi.org/10.1016/j.jogoh.2020.101967.

41. Alecsandru D, Barrio A, Garrido N, Aparicio P, Pellicer A, Moffett A, et al. Parental human leukocyte antigen-C allotypes are predictive of live birth rate and risk of poor placentation in assisted reproductive treatment. Fertil Steril. 2020;114(4):809-17. https://doi.org/10.1016/j.fertnstert.2020.05.008.

42. Zhang X, Gao Y, Liu W, Liu J, Wu L, Xiong S, et al. Frozen blastocyst embryo transfer vs. frozen cleavage-stage embryo transfer in couples with recurrent implantation failure: a cohort study. Hum Fertil. 2019. https://doi.org/10.1080/14647273.2019.1633021.

43. Revelli A, Canosa S, Carosso A, Filippini C, Paschero C, Gennarelli G, et al. Impact of the addition of Early Embryo Viability Assessment to morphological evaluation on the accuracy of embryo selection on day 3 or day 5: a retrospective analysis. J Ovarian Res. 2019;12:73.

44. Park DS, Kim JW, Chang EM, Lee WS, Yoon TK, Lyu SW. Strategies in the transfer of varying grades of vitrified-warmed blastocysts in women aged over 35 years: A propensity-matched analysis. J Obstet Gynaecol Res. 2019;45:849-57.

45. Freeman MR, Hinds MS, Howard KG, Howard JM, Hill GA. Guidance for elective single-embryo transfer should be applied to frozen embryo transfer cycles. J Assist Reprod Genet. 2019;36:939-46.

46. Tannus S, Hatirnaz S, Tan J, Ata B, Tan SL, Hatirnaz E, et al. Predictive factors for live birth after in vitro maturation of oocytes in women with polycystic ovary syndrome. Arch Gynecol Obstet. 2018;297:199-204.

47. Muteshi CM, Ohuma EO, Child T, Becker CM. The effect of endometriosis on live birth rate and other reproductive outcomes in ART cycles: A cohort study. Hum Reprod Open. 2018;2018:1-7.

48. Mehta V, Patel J, Gupta R, Shah S, Banker M. One plus one is better than two: Cumulative reproductive outcomes are better after two elective single blastocyst embryo transfers compared to one double blastocyst embryo transfer. J Hum Reprod Sci. 2018;11:161-8.

49. Dobson SJA, Lao MT, Michael E, Varghese AC, Jayaprakasan K. Effect of transfer of a poor quality embryo along with a top quality embryo on the outcome during fresh and frozen in vitro fertilization cycles. Fertil Steril. 2018;110:655-60.

50. Wintner EM, Hershko-Klement A, Tzadikevitch K, Ghetler Y, Gonen O, Wintner $\mathrm{O}$, et al. Does the transfer of a poor quality embryo together with a good quality embryo affect the In Vitro Fertilization (IVF) outcome? J Ovarian Res. 2017;10:2.

51. Tannus S, Son WY, Dahan MH. Elective single blastocyst transfer in advanced maternal age. J Assist Reprod Genet. 2017:34:741-8.

52. Mersereau J, Stanhiser J, Coddington C, Jones T, Luke B, Brown MB. Patient and cycle characteristics predicting high pregnancy rates with single-embryo transfer: an analysis of the Society for Assisted Reproductive Technology outcomes between 2004 and 2013. Fertil Steril. 2017:108:750-6.

53. Zhang N, Chen H, Xu Z, Wang B, Sun H, Hu Y. Pregnancy, Delivery, and Neonatal Outcomes of In Vitro Fertilization-Embryo Transfer in Patient with Previous Cesarean Scar. Med Sci Monit. 2016;22:3288-95.

54. Monteleone PA, Mirisola RJ, Gonçalves SP, Baracat EC, Serafini PC. Outcomes of elective cryopreserved single or double embryo transfers following failure to conceive after fresh single embryo transfer. Reprod BioMed Online. 2016;33:161-7.

55. Li M, Ma C, Zhao W, Li W, Zhao X, Ren W, et al. Pregnancy outcomes of single cleavage-stage embryo transfer in the ultra-short protocol. Int J Clin Exp Med. 2016:9:8760-4.

56. Keyhan S, Acharya KS, Acharya CR, Yeh JS, Provost MP, Goldfarb JM et al. How compliant are in vitro fertilization member clinics in following embryo transfer guidelines? An analysis of 59,689 fresh first in vitro fertilization autologous cycles from 2011 to 2012. Fertil Steril. 2016;106:645-52.e1.

57. He QH, Wang L, Liang LL, Zhang HL, Zhang CL, Li HS, et al. Clinical outcomes of frozen-thawed single blastocyst transfer in patients requiring whole embryo freezing. Syst Biol Reprod Med. 2016;62:133-8.

58. Hatırnaz S, Hatırnaz E, Dahan MH, Tan SL, Ozer A, Kanat-Pektas M, et al. Is elective single-embryo transfer a viable treatment policy in in vitro maturation cycles? Fertil Steril. 2016;106:1691-5.

59. Haikin Herzberger E, Ghetler Y, Tamir Yaniv R, Berkovitz A, Gonen O, Cohen I, et al. Time lapse microscopy is useful for elective singleembryo transfer. Gynecol Endocrinol. 2016;32:816-8. 
60. Crawford S, Boulet SL, Mneimneh AS, Perkins KM, Jamieson DJ, Zhang $Y$, et al. Costs of achieving live birth from assisted reproductive technology: a comparison of sequential single and double embryo transfer approaches. Fertil Steril. 2016;105:444-50.

61. Mounce G, McVeigh E, Turner K, Child TJ. Randomized, controlled pilot trial of natural versus hormone replacement therapy cycles in frozen embryo replacement in vitro fertilization. Fertil Steril. 2015;104:915-20.e1.

62. López Regalado ML, Clavero A, Gonzalvo MC, Serrano M, Martínez $L$, Mozas J, et al. Cumulative live birth rate after two single frozen embryo transfers (eSFET) versus a double frozen embryo transfer (DFET) with cleavage stage embryos: a retrospective cohort study. Assist Reprod Genet. 2014;31:1621-7.

63. Forman EJ, Hong KH, Franasiak JM, Scott RT Jr. Obstetrical and neonatal outcomes from the BEST Trial: single embryo transfer with aneuploidy screening improves outcomes after in vitro fertilization without compromising delivery rates. Am J Obstet Gynecol. 2014;210(157):e1-6.

64. Ercan CM, Kerimoglu OS, Sakinci M, Korkmaz C, Duru NK, Ergun A. Pregnancy outcomes in a university hospital after legal requirement for single-embryo transfer. Eur J Obstet Gynecol Reprod Biol. 2014;175:163-6.

65. Chai J, Yeung TWY, Lee VCY, Li RHW, Lau EYL, Yeung WSB, et al. Live birth rate, multiple pregnancy rate, and obstetric outcomes of elective single and double embryo transfers: Hong Kong experience. Hong Kong Med J. 2014;20:102-6.

66. Yilmaz N, Engin-Üstün $Y$, Inal H, Gorkem U, Bardakci Y, Gulerman C. The impact of single embryo transfer policy on pregnancy outcomes after legislative change. Gynecol Endocrinol. 2013;29:600-2.

67. Wu KL, Zhao HB, Liu H, Zhong WX, Yu GL, Chen ZJ. Elective single blastocyst transfer is more suitable for normal responders than for high responders. Chin Med J. 2013;126:2125-8.

68. Vélez MP, Kadoch IJ, Phillips SJ, Bissonnette F. Rapid policy change to single-embryo transfer while maintaining pregnancy rates per initiated cycle. Reprod BioMed Online. 2013;26:506-11.

69. Niinimäki M, Suikkari AM, Mäkinen S, Söderström-Anttila V, Martikainen $\mathrm{H}$. Elective single-embryo transfer in women aged $40-44$ years. Hum Reprod. 2013:28:331-5.

70. Bastu E, Celik C, Keskin G, Buyru F. Evaluation of embryo transfer time (day 2 vs day 3) after imposed single embryo transfer legislation: when to transfer? J Obstet Gynaecol. 2013;33:387-90

71. Virro MR, Winger EE, Reed JL. Intravenous immunoglobulin for repeated IVF failure and unexplained infertility. Am J Reprod Immunol. 2012;68:218-25.

72. Rodríguez Barredo DB, Tur Padro R, Mancini F, Parriego García M, Rodríguez García I, Coroleu Lletget B, et al. Elective single embryo transfer and cumulative pregnancy rate: five-year experience in a Southern European Country. Gynecol Endocrinol. 2012;28:425-8.

73. Gremeau AS, Brugnon F, Bouraoui Z, Pekrishvili R, Janny L, Pouly JL. Outcome and feasibility of elective single embryo transfer (eSET) policy for the first and second IVF/ICSI attempts. Eur J Obstet Gynecol Reprod Biol. 2012;160:45-50.

74. Guerif F, Frapsauce C, Chavez C, Cadoret V, Royere D. Treating women under 36 years old without top-quality embryos on day 2: a prospective study comparing double embryo transfer with single blastocyst transfer. Hum Reprod. 2011;26:775-81.

75. Friedman BE, Davis LB, Lathi RB, Westphal LM, Baker VL, Milki AA. Agerelated success with elective single versus double blastocyst transfer. ISRN Obst Gynecol. 2011. https://doi.org/10.5402/2011/656204.

76. Bissonnette F, Phillips SJ, Gunby J, Holzer H, Mahutte N, St-Michel P, et al. Working to eliminate multiple pregnancies: a success story in Québec. Reprod BioMed Online. 2011;23:500-4.

77. Barri PN, Coroleu B, Clua E, Tur R. Prevention of prematurity by single embryo transfer. J Perinat Med. 2011:39:237-40.

78. Wang YA, Kovacs G, Sullivan EA. Transfer of a selected single blastocyst optimizes the chance of a healthy term baby: a retrospective population based study in Australia 2004-2007. Hum Reprod. 2010;25:1996-2005

79. Sato W, Fukuda J, Kanamori K, Kawamura K, Kumagai J, Kodama H, et al. Evaluation of possible criteria for elective single embryo transfer. Reprod Med Biol. 2010:9:107-13.
80. Nakagawa K, Nishi Y, Sugiyama R, Kuribayashi Y, Sugiyama R, Inoue M. Elective single cleavage-stage embryo transfer need not result in lower pregnancy rates compared to double cleavage-stage embryo transfer. J Obstet Gynaecol Res. 2010;36:777-82

81. Fauque P, Jouannet P, Davy C, Guibert J, Viallon V, Epelboin S, et al. Cumulative results including obstetrical and neonatal outcome of fresh and frozen-thawed cycles in elective single versus double fresh embryo transfers. Fertil Steril. 2010;94:927-35.

82. Sundström P, Saldeen P. Cumulative delivery rate in an in vitro fertilization program with a single embryo transfer policy. Acta Obstet Gynecol Scand. 2009:88:700-6.

83. Roberts SA, Fitzgerald CT, Brison DR. Modelling the impact of single embryo transfer in a national health service IVF programme. Hum Reprod. 2009:24:122-31.

84. Bechoua S, Astruc K, Thouvenot S, Girod S, Chiron A, Jimenez C, et al. How to demonstrate that eSET does not compromise the likelihood of having a baby? Hum Reprod. 2009;24:3073-81.

85. Van Peperstraten AM, Kreuwel IA, Hermens RP, Nelen WL, Van Dop PA, Grol RP, et al. Determinants of the choice for single or double embryo transfer in twin prone couples. Acta Obstet Gynecol Scand. 2008;87:226-31.

86. Styer AK, Wright DL, Wolkovich AM, Veiga C, Toth TL. Single-blastocyst transfer decreases twin gestation without affecting pregnancy outcome. Fertil Steril. 2008;89:1702-8.

87. Kalu E, Thum MY, Abdalla H. Reducing multiple pregnancy in assisted reproduction technology: towards a policy of single blastocyst transfer in younger women. Bjog. 2008;115:1143-50.

88. Lundin K, Bergh C. Cumulative impact of adding frozen-thawed cycles to single versus double fresh embryo transfers. Reprod BioMed Online. 2007:15:76-82.

89. Donoso P, Verpoest W, Papanikolaou EG, Liebaers I, Fatemi HM, Sermon $K$, et al. Single embryo transfer in preimplantation genetic diagnosis cycles for women $<36$ years does not reduce delivery rate. Hum Reprod. 2007;22:1021-5.

90. Veleva Z, Vilska S, Hydén-Granskog C, Tiitinen A, Tapanainen JS, Martikainen $\mathrm{H}$. Elective single embryo transfer in women aged 36-39 years. Hum Reprod. 2006;21:2098-102.

91. Le Lannou D, Griveau JF, Laurent MC, Gueho A, Veron E, Morcel K. Contribution of embryo cryopreservation to elective single embryo transfer in IVF-ICSI. Reprod BioMed Online. 2006;13:368-75.

92. Kjellberg AT, Carlsson P, Bergh C. Randomized single versus double embryo transfer: obstetric and paediatric outcome and a cost-effectiveness analysis. Hum Reprod. 2006:21:210-6.

93. Saldeen P, Sundström P. Would legislation imposing single embryo transfer be a feasible way to reduce the rate of multiple pregnancies after IVF treatment? Hum Reprod. 2005;20:4-8.

94. Henman M, Catt JW, Wood T, Bowman MC, De Boer KA, Jansen RPS. Elective transfer of single fresh blastocysts and later transfer of cryostored blastocysts reduces the twin pregnancy rate and can improve the in vitro fertilization live birth rate in younger women. Fertil Steril. 2005;84:1620-7

95. Hara T, Katsuki T, Kusuda T, Ohama K. Pregnancy rate, multiple pregnancy rate, and embryo quality: Clues for single blastocyst transfer from double blastocyst transfer in an unselected population. Reprod Med Biol. 2005;4:153-60.

96. Criniti A, Thyer A, Chow G, Lin P, Klein N, Soules M. Elective single blastocyst transfer reduces twin rates without compromising pregnancy rates. Fertil Steril. 2005:84:1613-9.

97. Martikainen H, Orava M, Lakkakorpi J, Tuomivaara L. Day 2 elective single embryo transfer in clinical practice: better outcome in ICSI cycles. Hum Reprod. 2004:19:1364-6.

98. Kuramoto T, Boediono A, Egashira A, Motoishi M, Sugioka M, Fukuda K, et al Selected single blastocyst transfers maintained pregnancy outcome and eliminated multiple pregnancies. Reprod Med Biol. 2004;3:13-8.

99. Gerris J, De Sutter P, De Neubourg D, Van Royen E, Vander Elst J, Mangelschots K, et al. A real-life prospective health economic study of elective single embryo transfer versus two-embryo transfer in first IVF/ ICSI cycles. Hum Reprod. 2004;19:917-23.

100. Rutherford AJ, Subak-Sharpe RJ, Dawson KJ, Margara RA, Franks S, Winston RML. Improvement of in vitro fertilisation after treatment with buserelin, an agonist of luteinising hormone releasing hormone. $\mathrm{Br}$ Med J. 1988:296:1765-8. 
101. Speirs AL, Lopata A, Gronow MJ. Analysis of the benefits and risks of multiple embryo transfer. Fertil Steril. 1983;39:468-71.

102. Meldrum DR, Adashi EY, Garzo VG, Gleicher N, Parinaud J, Pinborg A, et al. Prevention of in vitro fertilization twins should focus on maximizing single embryo transfer versus twins are an acceptable complication of in vitro fertilization. Fertil Steril. 2018;109:223-9.

103. Gleicher N, Barad D. The relative myth of elective single embryo transfer. Hum Reprod. 2006;21:1337-44.

104. Sundhararaj UM, Madne MV, Biliangady R, Gurunath S, Swamy AG, Gopal IST. Single Blastocyst Transfer: The Key to Reduce Multiple Pregnancy Rates Without Compromising the Live Birth Rate. J Hum Reprod Sci. 2017;10:201-7.

105. Tao T, Robichaud A, Mercier J, Ouellette R. Influence of group embryo culture strategies on the blastocyst development and pregnancy outcome. J Assist Reprod Genet. 2013;30:63-8.

106. Teklenburg G, Salker M, Molokhia M, Lavery S, Trew G, Aojanepong T, et al. Natural selection of human embryos: decidualizing endometrial stromal cells serve as sensors of embryo quality upon implantation. PLoS One. 2010;5:e10258.

107. Takeshima K, Jwa SC, Saito H, Nakaza A, Kuwahara A, Ishihara O, et al. Impact of single embryo transfer policy on perinatal outcomes in fresh and frozen cycles-analysis of the Japanese Assisted Reproduction Technology registry between 2007 and 2012. Fertil Steril. 2016;105:337-46. e3.

108. Hayashi M, Satoh S, Matsuda Y, Nakai A. The effect of single embryo transfer on perinatal outcomes in Japan. Int J Med Sci. 2015;12:57-62.

109. Kissin DM, Kulkarni AD, Kushnir VA, Jamieson DJ. Number of embryos transferred after in vitro fertilization and good perinatal outcome. Obstet Gynecol. 2014;123:239-47.

110. Chambers GM, Hoang VP, Lee E, Hansen M, Sullivan EA, Bower C, et al. Hospital costs of multiple-birth and singleton-birth children during the first 5 years of life and the role of assisted reproductive technology. JAMA Pediatr. 2014;168:1045-53.

111. Treweek S, Zwarenstein M. Making trials matter: pragmatic and explanatory trials and the problem of applicability. Trials. 2009;10:37.

112. Yland J, Messerlian C, Minguez-Alarcon L, Ford JB, Hauser R, Williams PL. Methodological approaches to analyzing IVF data with multiple cycles. Hum Reprod. 2019;34:549-57.

\section{Publisher's Note}

Springer Nature remains neutral with regard to jurisdictional claims in published maps and institutional affiliations.

Ready to submit your research? Choose BMC and benefit from:

- fast, convenient online submission

- thorough peer review by experienced researchers in your field

- rapid publication on acceptance

- support for research data, including large and complex data types

- gold Open Access which fosters wider collaboration and increased citations

- maximum visibility for your research: over $100 \mathrm{M}$ website views per year

At BMC, research is always in progress.

Learn more biomedcentral.com/submissions 